\title{
Effect of castration on prostaglandin-mediated changes in membrane potential and prostaglandin synthesis in guinea-pig seminal vesicle tissue
}

\author{
N. Levine, M. E. Gerritsen, C. Carbonaro and N. Tarlin \\ Physiology Department, New York Medical College, Valhalla, NY 10595, U.S.A.
}

\begin{abstract}
Summary. Arachidonic acid stimulated an increase in transmural electrical potential difference (p.d.) in guinea-pig seminal vesicle tissue in vitro. Pretreatment with indomethacin abolished this response. Indomethacin pretreatment did not prevent the p.d. from increasing in response to theophylline. Changes in p.d. in response to arachidonic acid were greatly attenuated, and the response to theophylline was abolished in seminal vesicle tissue taken from castrated guinea-pigs. Seminal vesicles, aorta and ileum taken from castrated guinea-pigs synthesized and released more prostaglandins than did those from control animals. It is concluded that (1) the effects of arachidonic acid on p.d. are mediated by its metabolism to prostaglandins; (2) the inability of seminal vesicles from castrated animals to respond to arachidonic acid is not a result of a decrease in prostaglandin production, but is more likely a result of other degenerative changes attendant upon castration; and (3) androgens appear to have some regulatory function on prostaglandin synthesis in a variety of tissues.
\end{abstract}

\section{Introduction}

Prostaglandins increase the transmural potential difference and 'short-circuit' current in flat sheets of guinea-pig seminal vesicle mounted in Ussing-type chambers. The mechanism for stimulating these increases appears to be through stimulation of active $\mathrm{Cl}^{-}$secretion into the mucosal solution (Levine, Rinaldo \& Schultz, 1975). Prostaglandin (PG) E-2 will inhibit net $\mathrm{Na}^{+}, \mathrm{K}^{+}$and $\mathrm{H}_{2} \mathrm{O}$ resorption when added to a solution perfusing the guinea-pig seminal vesicle in vivo. However, pretreatment of guinea-pigs with indomethacin does not alter net transport rates of $\mathrm{Na}^{+}, \mathrm{K}^{+}$or $\mathrm{H}_{2} \mathrm{O}$ when measured in guinea-pig seminal vesicles perfused in vivo (Levine \& Kelly, 1980). Levine \& Kelly (1980) also demonstrated that castration causes a complete cessation of net $\mathrm{Na}^{+}, \mathrm{K}^{+}$and $\mathrm{H}_{2} \mathrm{O}$ resorption by guinea-pig seminal vesicles perfused in vivo. These authors were able to maintain normal resorptive rates by treating the guinea-pigs with testosterone or $5 \alpha$-dihydrotestosterone.

These observations raise the question as to whether or not the effects of $P G$, in vitro or in vivo, represent physiological or pharmacological modifications of seminal vesicle function. An additional question relates to the role that androgens may play in modulating the actions of PGs.

\section{Materials and Methods}

Experiments were performed on male guinea-pigs weighing between 650 and $900 \mathrm{~g}$.

Technique for measuring transmural membrane potential in vitro. The basic techniques for measuring transmural electrical potential differences (p.d.) in guinea-pig seminal vesicle in vitro have been described in detail previously (Levine et $a l_{9 v 1975}$ ) Briefly seminal vesicles were excised 
from guinea-pigs anaesthetized with pentobarbitone sodium, the vesicles were slit open to form a flat sheet, the vesicular contents were washed out, and a section of the tissue was mounted between two Plexiglass half-chambers. Both surfaces of the tissue were bathed in $10 \mathrm{ml}$ Ringer-bicarbonate buffer $\left(25 \mathrm{~mm}-\mathrm{HCO}_{3} ; \mathrm{pH} 7.4\right.$ when gassed with $5 \% \mathrm{CO}_{2}: 95 \% \mathrm{O}_{2}$ at $\left.37^{\circ} \mathrm{C}\right)$. In all experiments, the buffer contained $10 \mathrm{~mm}$-glucose and $10 \mathrm{~mm}$-glutamine. The potential difference was determined by using agar electrodes that were inserted into both half-chambers. The electrodes were connected to calomel reference cells which, in turn, were connected to an electrometer (Keithly 600B).

Effect of castration on potential difference and the response to arachidonic acid. At 7 days before the experiment, guinea-pigs were anaesthetized with ether and bilaterally castrated through a small scrotal incision. The efferent ductules and blood vessels at the pampiniform plexus were ligated. On the day of the experiment control (uncastrated) or castrated guinea-pigs were anaesthetized with pentobarbitone sodium and the seminal vesicles excised and prepared for measurement of potential difference as described above. At $45 \mathrm{~min}$ after the vesicles were mounted in the half-chambers, arachidonic acid was added to the solutions bathing the mucosal and serosal surfaces. The concentration of arachidonic acid in the bathing medium was $8.3 \times 10^{-6} \mathrm{M}\left(25 \mu \mathrm{l}\right.$ of a $3.3 \times 10^{-3} \mathrm{M}^{-}$ solution of arachidonic acid dissolved in $100 \mathrm{mM}-\mathrm{Na}_{2} \mathrm{CO}_{3}$ was added to each side). Potential difference was then measured for an additional $30 \mathrm{~min}$.

Effect of indomethacin on changes in potential difference in response to arachidonic acid. Normal guinea-pigs were anaesthetized with pentobarbitone sodium and both seminal vesicles were excised and prepared for measurement of potential difference as described above. Indomethacin was added to the solution bathing both surfaces of one of the vesicles. The concentration of indomethacin in the bathing solution was $2.5 \mu \mathrm{g} / \mathrm{ml}$. Arachidonic acid $\left(8.3 \times 10^{-6} \mathrm{M}\right)$ was added to the solutions bathing each vesicle at $25 \mathrm{~min}$ after addition of indomethacin. The potential difference was measured for an additional $20 \mathrm{~min}$.

Effect of indomethacin on changes in potential difference in response to theophylline. One of each pair of seminal vesicles was exposed to indomethacin for $25 \mathrm{~min}$ as described above. Theophylline (10 mM final concentration in bathing solution) was then added to each vesicle pair and the potential difference was measured for an additional $20 \mathrm{~min}$.

Effect of castration on changes in potential difference in response to theophylline. Five guinea-pigs were castrated as described above, 7 days before the experiment. On the day of the experiment the seminal vesicles were excised, mounted in the chambers and potential difference measured as described. At $35 \mathrm{~min}$ after being mounted, theophylline $(10 \mathrm{mM}$ final concentration in bathing solution) was added to both surfaces of the tissue, and potential difference was recorded for an additional $20 \mathrm{~min}$.

Effect of castration on formation of PGs from $\left[1-{ }^{14} \mathrm{C}\right]$ arachidonic acid in vitro. Guinea-pigs were castrated 7 days before the experiment as described above. On the day of the experiment the 5 castrated guinea-pigs and 5 normal age-matched controls were killed by cervical dislocation and the seminal vesicles, thoracic aorta and ileum were excised.

The seminal vesicles were slit open and the contents gently washed out with phosphate-buffered saline (PBS) (pH 7.4). The vesicles were cut into segments of about $3 \times 3 \mathrm{~mm}$ and weighed. Seminal vesicle wet weights (mean \pm s.e.m.) were $0.39 \pm 0.04 \mathrm{~g}$ in controls and $0.25 \pm 0.03 \mathrm{~g}$ in the castrates.

After blood and connective tissue was removed from the thoracic aorta it was cut into rings about $3 \mathrm{~mm}$ wide. The wet weight of the group of rings taken from controls was identical to that taken from the castrated guinea-pigs $(0.04 \pm 0.01 \mathrm{~g} /$ wet weight in each group). The ileum was cut into segments of about $3 \times 3 \mathrm{~mm}$ after the ileal contents had been washed out with PBS; wet weight values were $0.6 \pm 0.2 \mathrm{~g}$ for the controls and $0.48 \pm 0.04 \mathrm{~g}$ for the castrates.

The various tissue segments were then incubated with $5 \mu \mathrm{Ci}[1-14 \mathrm{C}] \mathrm{arachidonic}$ acid/sample (sp. act. $56.4 \mathrm{mCi} / \mathrm{mmol}$; Amersham, Boston, MA) for $4 \mathrm{~h}$ in Dulbecco's Modified Eagle's Medium 
(Gibco; Grand Island, N.Y.) at $37^{\circ} \mathrm{C}$ in $5 \% \mathrm{CO}_{2}$ in air (pH 7.4). After incubation, the medium was removed and extracted with 4 volumes of ethyl acetate-methanol- $0 \cdot 2 \mathrm{M}$-citric acid $(15: 2: 1$, by vol.). Extraction efficiency was $85-90 \%$. The organic phase was evaporated in vacuo, the residue resuspended in ethyl acetate and applied to heat-activated silica gel $\mathrm{G}$ thin-layer plates (Analtech, Newark, DE). Chromatograms were developed in the organic phase of ethyl acetate-hexaneacetic acid-water ( $56: 24: 12: 60$, by vol.). The PG products were identified by comigration with authentic standards as described in earlier studies (Gerritsen \& Printz, 1981; Gerritsen, 1983; Gerritsen \& Cheli, 1983). The products were quantified by radiochromatogram scanning (Packard 7201 ) and liquid scintillation counting. Metabolite production is expressed as pmol product/g wet wt tissue $/ 4 \mathrm{~h}$ as calculated from the d.p.m. obtained using a quench curve and the external standards ratio method.

Endogenous production of PGE-2 and 6-keto PGF-1 $\alpha$ by seminal vesicles as measured by radioimmunoassay. Guinea-pigs were castrated as described above, 7 days before the experiment. On the day of the experiment the guinea-pigs were killed by cervical dislocation and the seminal vesicles removed and prepared for incubation in a manner identical to that described in the previous section. Eight normal and 8 castrated guinea-pigs were used. The tissues were incubated for $15 \mathrm{~min}$ at $37^{\circ} \mathrm{C}$ in $5 \mathrm{ml} \mathrm{PBS}$ ( $\mathrm{pH} \mathrm{7.4}$ ). The buffer was removed and concentrations of PGE-2 and 6-keto PGF- $1 \alpha$ (the stable hydrolytic product of PGI-2) were measured by radioimmunoassay. The results were expressed as $\mathrm{pg} P \mathrm{PG}$ produced $/ \mathrm{g}$ wet wt tissue $/ 15 \mathrm{~min}$.

The radioimmunoassay has been described in detail previously (Gerritsen \& Cheli, 1983). Briefly, the concentrations of PGE-2 and 6-keto PGF-1 $\alpha$ were determined on non-extracted samples of PBS. Antisera were kindly supplied by Dr Lawrence Levine (Brandeis University, Waltham, MA). The detection limit for both antisera was $2 \mathrm{pg} /$ tube and intra- and interassay variation were routinely $<10 \%$. The antiserum to 6-keto PGF- $1 \alpha$ demonstrated some crossreactivity with 6-keto PGE-2 (3.1\%), 6,15-diketo PGF-1 $\alpha(1.0 \%)$ and PGF-2 $\alpha(0 \cdot 3 \%)$. The remaining prostanoids tested (13,14-dihydro-6,15-diketo PGF-1 $\alpha$, PGE-2, thromboxane B-2, PGA-2 and arachidonic acid) exhibited cross-reactivity of $<0.03 \%$. The antiserum directed against PGE-2 was not as specific. Complete cross-reactivity was exhibited with PGA-2 (150\%), and detectable cross-reactivity was exhibited with PGE-1 (25.6\%), PGD-2 (0.4\%), PGF-2 $\alpha(0 \cdot 3 \%)$, 6-keto PGE-1 (10.1\%), and 15-keto PGE-2 (2.6\%). Cross-reactivity with other metabolites of the arachidonic acid cascade (thromboxane B-2, 6-keto PGF-1 $\alpha, 13$, 14-dihydro-6,15-diketo PGF-1 $\alpha$ ) and arachidonic acid itself was $<0.01 \%$.

\section{Results}

\section{Transmural electrical potential differences}

Normal animals. Addition of arachidonic acid to seminal vesicle tissue taken from normal guinea-pigs elicited a prompt rise in potential difference that reached a maximum in 8 min (Textfig. 1). The maximal increment above the potential difference measured at the time of arachidonic acid addition was $2.5 \pm 0.4 \mathrm{mV}(P<0.001$, paired $t$ test, $n=17)$. The potential difference slowly decreased after $8 \mathrm{~min}$ but was still significantly elevated $30 \mathrm{~min}$ after arachidonic acid addition $(P$ $<0.01$, paired $t$ test, $n=17)$. Theophylline caused a prompt rise in potential difference that reached a maximum in $5 \pm 1 \mathrm{~min}$. The maximum increment was $4.4 \pm 0.9 \mathrm{mV}(P<0.001$, paired $t$ test, $n=9$ ).

Castrated animals. There were three distinct differences in the potential difference measured in vitro for seminal vesicles taken from castrated animals (Text-fig. 1). (1) The potential difference measured before addition of arachidonic acid was significantly lower than that measured in control animals $(P<0.001$, Student's $t$ test d.f. $=30:$ comparisons at $-45 \mathrm{~min},-30 \mathrm{~min},-15 \mathrm{~min}, 0$ $\mathrm{min}$ ). (2) The maximum increment in potential difference after arachidonic acid addition was only $0.5 \pm 0.1 \mathrm{mV}(n=15)$, significantly less than the maximum increment observed in the control 


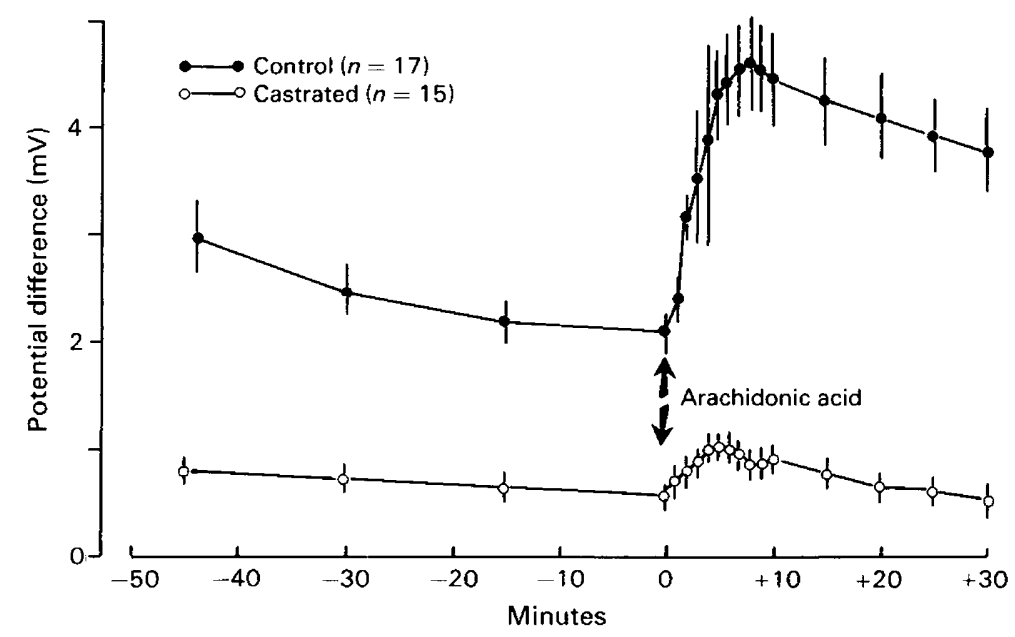

Text-fig. 1. Effects of 7 days castration on changes in seminal vesicle potential difference in response to arachidonic acid $\left(8.3 \times 10^{-6} \mathrm{M}\right)$. Each value is mean \pm s.e.m. Mucosal surface is negative.

guinea-pigs $(P<0.001$, Student's $t$ test; d.f. $=30)$. (3) The increase that did occur, although significant, lasted only $15 \mathrm{~min}$ compared with at least $30 \mathrm{~min}$ in control animals. In addition, seminal vesicles taken from castrated guinea-pigs did not respond to theophylline with an increase in potential difference: the maximum increment was $0.04 \pm 0.04 \mathrm{mV}(P<0.3 ; n=5$; paired $t$ test).

Effects of indomethacin. Treatment with indomethacin for $25 \mathrm{~min}$ before addition of arachidonic acid completely prevented the seminal vesicle tissue from responding to arachidonic acid with an increase in potential difference (Text-fig. 2). The untreated tissue from each guinea-pig responded with significant increases in potential difference $(P<0.001$, paired $t$ test, $n=5)$. However, indomethacin treatment did not prevent the seminal vesicle tissue from responding to theophylline. The maximum increment in potential difference was $3.8 \pm 0.8 \mathrm{mV}$ for the 9 tissue samples treated with indomethacin and $4.4 \pm 0.9 \mathrm{mV}$ for the untreated tissue from the same animals. The time course for the response was also the same for both groups of vesicles (maximum increment in potential difference was reached $5 \pm 1 \mathrm{~min}$ after addition of theophylline).

\section{Prostaglandin production}

Metabolism of exogenous $\left[1-{ }^{14} \mathrm{C}\right]$ arachidonic acid. There was a general tendency for overall PG production to increase after castration in seminal vesicles, aorta and ileum (Table 1). The aorta produced more of all of the PG products measured under these experimental conditions than did the seminal vesicles or the ileum. This was true for tissues taken from castrated or control guineapigs $(P<0.001$ in all instances; Student's $t$ test).

Endogenous release. Seminal vesicle tissue taken from castrated guinea-pigs released significantly more PGE-2 than did tissue taken from normal guinea-pigs $(9 \pm 2$ and $4 \pm 1 \mathrm{pg} / \mathrm{g}$ tissue $/ 15$ min, respectively; $n=8$ for both; $P<0 \cdot 05$ ). The amount of 6 -keto PGF- $1 \alpha$ released by seminal vesicle tissue taken from castrated guinea-pigs tended to be greater than that released by vesicle tissue from control animals ( $110 \pm 40$ and $40 \pm 12 \mathrm{pg} / \mathrm{g}$ tissue $/ 15 \mathrm{~min}$ respectively; $n=8$ for both). Significantly more of the 6-keto PGF-1 $\alpha$ was released than PGE-2 by vesicle tissue taken from castrated $(P<0.02)$ or control $(P<0.01)$ guinea-pigs. 


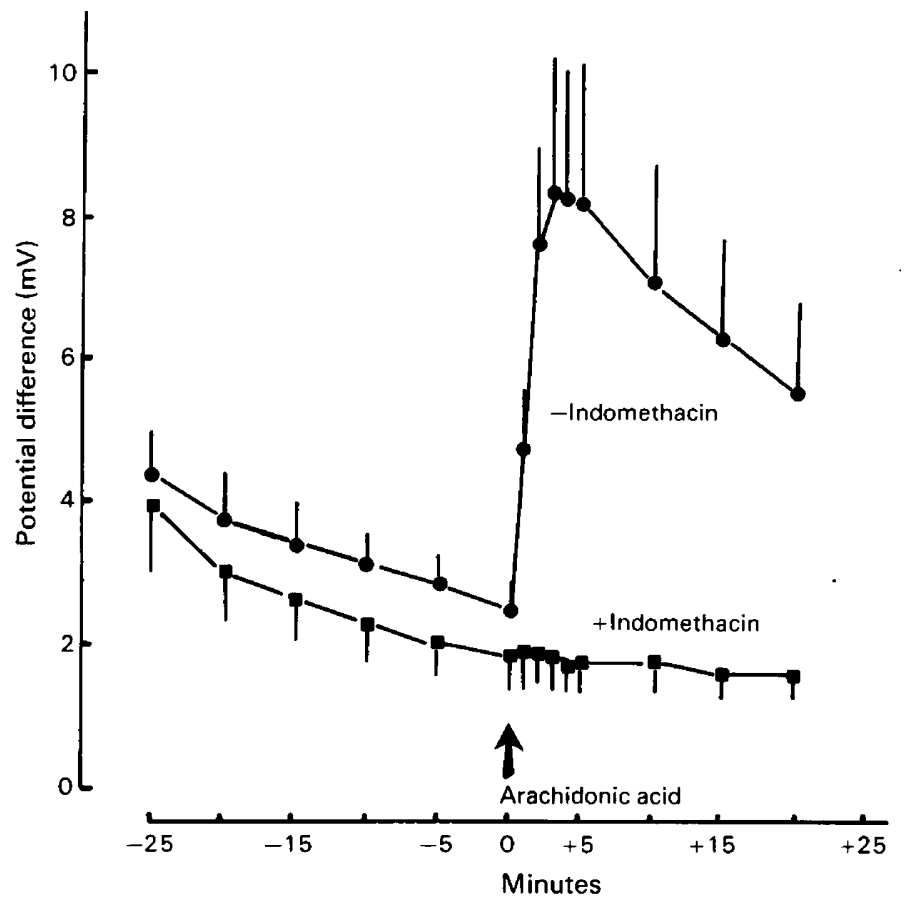

Text-fig. 2. Effects of indomethacin pretreatment $(2.5 \mu \mathrm{g} / \mathrm{ml}$ in bath) on changes in seminal vesicle potential difference in response to arachidonic acid $\left(8.3 \times 10^{-6} \mathrm{M}\right.$ in bath). Indomethacin was added to buffer bathing one of a pair of vesicles at $-25 \mathrm{~min}$. Values are mean \pm s.e.m. $(n=5)$. Mucosal surface negative.

Table 1. Production of prostaglandins from $\left[1-{ }^{14} \mathrm{C}\right]$ arachidonic acid by guinea-pig tissue in vitro

Product (pmol/g tissue/4 h)

\begin{tabular}{llccccc}
\multicolumn{1}{c}{ Tissue } & Group & 6-keto PGF-1 $\alpha$ & PGF-2 $\alpha$ & PGE-2 & PGD-2 & Total \\
\hline Seminal vesicle & Control & $10 \pm 2$ & $7 \pm 1$ & $5 \pm 1$ & $5 \pm 1$ & $27 \pm 6$ \\
& Castrated & $22 \pm 8$ & $16 \pm 3^{*}$ & $15 \pm 2^{*}$ & $7 \pm 1$ & $63 \pm 15^{* *}$ \\
Ileum & Control & $6 \pm 1$ & $9 \pm 2$ & $9 \pm 2$ & $4 \pm 2$ & $33 \pm 5$ \\
& Castrated & $11 \pm 2^{* *}$ & $14 \pm 1^{* *}$ & $10 \pm 1$ & $8 \pm 1$ & $43 \pm 4$ \\
Aorta ${ }^{*}$ & Control & $150 \pm 16$ & $147 \pm 12$ & $224 \pm 32$ & $74 \pm 9$ & $597 \pm 53$ \\
& Castrated & $209 \pm 35$ & $170 \pm 27$ & $374 \pm 51^{*}$ & $70 \pm 18$ & $849 \pm 221$ \\
\hline
\end{tabular}

Values are mean \pm s.e.m. $(n=5)$.

Significantly greater than control value: $* P<0.05 ; * * P<0.01$.

+ Aorta produced more prostaglandins than did seminal vesicle or ileum $(P<0.001)$.

\section{Discussion}

We have previously demonstrated that prostaglandins can alter transmural electrical potential differences, ion and water transport in seminal vesicles both in vivo and in vitro (Levine et al., 1975; Levine \& Kelly, 1980). However, the question remained as to whether the observed effects had any physiological significance. It is apparent from the results presented in this paper that (1) the electrical response of the seminal vesicle to arachidonic acid, in vitro, is similar to that previously 
reported for the vesicular response to prostaglandins; and (2) the response to arachidonic acid is mediated by the formation of prostaglandins since indomethacin pretreatment completely inhibits the response to arachidonic acid. These data suggest that prostaglandins may play an integral role in regulating ion and water transport in the seminal vesicle.

The mechanism through which prostaglandins modulate ion transport is not completely clear. In some tissues prostaglandins are known to stimulate ion transport through activation of the adenylate cyclase system, or, in some other manner, stimulate an increase in intracellular concentration of 3'5'-cAMP (Hendrix \& Paulk, 1977). However, in other tissues, prostaglandins alter ion and water transport by inhibiting formation of 3'5'-cAMP (Schrier, Berl, Anderson \& McDonald, 1977). In an earlier study, we demonstrated involvement of $3^{\prime} 5^{\prime}$-cAMP in ion movements in the seminal vesicle (Levine et al., 1975). In addition, treatment with theophylline, an inhibitor of cyclic nucleotide phosphodiesterase, elicits increases in potential difference in both control and indomethacin-pretreated seminal vesicle tissue. It is therefore likely that prostaglandin-elicited changes in potential difference and ion transport in the seminal vesicle are mediated via changes in intracellular activity of $3^{\prime} 5^{\prime}$-cAMP. Forskolin, a specific activator of adenylate cyclase (Daly, 1984), also stimulated an increase in potential difference in guinea-pig seminal vesicle in vitro ( $\mathbf{N}$. Levine, unpublished observations).

Seminal vesicles taken from castrated guinea-pigs do not demonstrate any substantial electrical response to addition of arachidonic acid, and the spontaneous potential difference is significantly lower than that measured in vesicles taken from control animals. These observations are in accord with our previous demonstration that, in vivo, seminal vesicles in castrated animals do not resorb $\mathrm{Na}^{+}, \mathrm{K}^{+}$or $\mathrm{H}_{2} \mathrm{O}$ (Levine \& Kelly, 1980). Nonetheless, seminal vesicle tissue taken from castrated guinea-pigs synthesized and released more prostaglandins than did tissue from control animals. Therefore, the defect in ion transport in androgen-deprived seminal vesicles is probably not related to decreased synthesis of prostaglandins but is probably a reflection of the cumulative effect of the degenerative changes in the seminal vesicle resulting from castration. This conclusion is reinforced by the observation that seminal vesicle tissue from castrated guinea-pigs does not respond to theophylline. There may be a decrease in the amount of transport proteins or channels, a decline in the secondary effector system (adenylate cyclase-cAMP), or other changes in enzymes and proteins needed to maintain ion transport and electrical gradients. It is also possible that castration may result in changes in the concentrations of circulating hormones that affect ion transport. For example, it has been demonstrated that androgens increase the binding of angiotensin and ultimately increase aldosterone secretion by bovine adrenal glomerulosa cells in vitro (Carroll \& Goodfriend, 1984). We are unaware of any studies linking aldosterone secretion to ion transport in seminal vesicles.

Increased production of prostaglandins was observed in the 3 tissues studied, i.e. aorta, ileum and seminal vesicle. This increase could be demonstrated by measuring $\left[1-{ }^{14} \mathrm{C}\right]$ arachidonic acid metabolism or release of prostaglandins synthesized from endogenous arachidonic acid. Glucocorticoids have been shown to inhibit prostaglandin synthesis by inhibiting phospholipase $A_{2}$ activity. Phospholipase $A_{2}$ mediates the release of arachidonate from membrane phospholipids (Hirata, Schiffman, Venkatasubramanian, Salomon \& Axelrod, 1980; Blackwell et al., 1982). The results from this study indicate that circulating androgens may also exert a modulatory influence on prostaglandin synthesis. Testosterone has been shown to inhibit PGI-2 formation by rat aortic smooth muscle cells in culture (Nakao, Chang, Murota \& Orimo, 1981). The level at which this influence is exerted is unknown. From the present study, the enhanced conversion of exogenous arachidonic acid to prostaglandins may indicate that one possible site of androgen influence is at the level of the cyclo-oxygenase step in arachidonic acid conversion.

We thank Ms J. Yu, Ms C. Cheli and Ms A. Rodrigues for technical assistance. Financial support was provided by grants from the March of Dimes Birth Defects Foundation (N.L.); NIH HL 26998 and the American Heart Association (M.E.G.). 


\section{References}

Blackwell, G.J., Carnuccio, R., DiRosa, M., Flower, R.J., Langham, C.S.J., Parente, L., Persico, P., RusselSmith, N.C. \& Stone, D. (1982) Glucocorticoids induce the formation and release of anti-inflammatory and anti-phospholipase proteins into the peritoneal cavity of the rat. Br. J. Pharmac. 76, 185-194.

Carroll, J.E. \& Goodfriend, T.L. (1984) Androgen modulation of adrenal angiotensin receptors. Science, N.Y. 224, 1009-1011.

Daly, J.W. (1984) Forskolin, adenylate cyclase and cell physiology: an overview. In Advances in Cyclic Nucleotide and Protein Phosphorylation Research, Vol. 17, pp. 81-89. Eds P. Greengard, G. A. Robison, R. Paoletti \& S. Nicosia. Raven Press, New York.

Gerritsen, M.E. (1983) PGD $_{2}$ formation in the vasculature. Characteristics of rat tail vein prostaglandin endoperoxide D isomerase. Prostaglandins 28, 105120.

Gerritsen, M.E. \& Cheli, C.D. (1983) Arachidonic acid and prostaglandin endoperoxide metabolism in isolated rabbit coronary microvessels and isolated and cultivated coronary microvessel endothelial cells. $J$. clin. Invest. 72, 1658-1671.

Gerritsen, M.E. \& Printz, M.P. (1981) Sites of prostaglandin synthesis in the bovine heart and isolated bovine coronary microvessels. Circ. Res. 49, 11521163.
Hendrix, T.R. \& Paulk, H.T. (1977) Intestinal secretion. In Gastrointestinal Physiology. II. International Review of Physiology, Vol. 12, pp. 257-284. Ed. R. K. Crane. University Park Press, Baltimore.

Hirata, F., Schiffman, E., Venkatasubramanian, K., Salomon, D. \& Axelrod, J. (1980) A phospholipase A, inhibitory protein in rabbit neutrophils induced by glucocorticoids. Proc. natn. Acad. Sci. U.S.A. 77, 2533-2536.

Levine, N. \& Kelly, H. (1980) Control of reabsorption of water and electrolytes by guinea-pig seminal vesicle in vivo. J. Reprod. Fert. 58, 421-427.

Levine, N., Rinaldo, J.E. \& Schultz, S.G. (1975) Active chloride secretion by in vitro guinea-pig seminal vesicle and its possible relation to vesicular function in vivo. J. Physiol., Lond. 246, 197-211.

Nakao, J., Chang, W.-C., Murota, S.-I. \& Orimo, H. (1981) Testosterone inhibits prostacyclin production by rat aortic smooth muscle cells in culture. Atherosclerosis 39, 203-209.

Schrier, R.W., Berl, T., Anderson, R.J. \& McDonald, K.M. (1977) Nonosmolar control of renal water excretion. In Disturbances in Body Fluid Osmolality, pp. 149-178. Eds T. E. Andreoli, J. J. Grantham \& F. C. Rector, Jr. American Physiological Society, Bethesda.

Received 1 August 1984 